\title{
EDUCAÇÃO FÍSICA NA ESCOLA: FORMANDO, CONFORMANDO, TRANSFORMANDO
}

\author{
GILMAR DE CARVALHO CRUZ *
}

CRUZ, G. de C. Educação Física na escola: formando, conformando, transformando. Semina:

Ci. Sociais/Humanas, Londrina, v. 17, n. 3, p. 338-344, set. 1996.

RESUMO: Ao considerarmos as possibilidades de atuação da Educação Física na escola, emergem de imediato questões relacionadas ao contexto social em seu sentido mais amplo. Tendo a escola o papel de formar o cidadão, a Educação Física, conseqüentemente, também assume parcela de responsabilidade nessa tarefa. Entretanto, deve-se atentar ao fato de que essa intervenção na vida escolar refletirá nos cidadãos por vir. As intervenções no cotidiano escolar podem colaborar tanto para a conformação quanto para a transformação do indivíduo e seu ambiente social. Uma Educação Física apoiada em pressupostos teórico-metodológicos crítico-criativos e que almeja uma participação efetiva no projeto sócio-políticopedagógico da escola supōe um rompimento radical com a perspectiva reducionista, desportivocompetitivista, que é preponderante em nossas escolas.

\section{PALAVRAS-CHAVE: Educação Física / Escola / Desporto / Cidadania}

O sistema educacional apóia-se no primado de educar o cidadão. Esforços conjugados de várias disciplinas unem-se neste sentido. A Educação Física é uma dessas disciplinas que, tanto quanto as demais, encontra-se eivada por elementos que traduzem as vicissitudes sociais que permeiam o cotidiano escolar, tais como desigualdades econômico-sociais, preconceito e tantas outras. Profissionais que atuam nessa área específica de conhecimento defrontam-se por vezes com questões que, de longe, ultrapassam os limites arquitetônico-materiais da escola.

Em decorrência desse enfrentamento intrínseco à prática pedagógica, aflora a angústia de vivenciar-se um sentimento de impotência ante as demandas sociais, refletidas nos alunos e nos próprios professores. Este sentimento leva-nos a um (re)pensar sobre a ação desenvolvida nesse processo formal de ensino e como ela contribui, ou poderia contribuir, à superação do estágio atual - preponderantemente competitivista (Moreira, 1991; 1992; Picollo, 1993) - onde se encontra a Educação Física no contexto educacional. Parecenos necessário que essa disciplina, respaldada em seus conteúdos específicos -jogos, esporte, ginástica, dança - atente a sua participação no processo histórico de elaboração da Educação brasileira.

No que diz respeito à Educação do cidadão vale destacar, como sinalizam O'Donnel (1988) e Paiva (1991), a comunhão estabelecida entre a cidadania e as demandas político-econômico-sociais presentes em cada momento do percurso histórico da humanidade. Ao falarmos em cidadania, remetemo-nos aos preceitos orientadores da infra-estrutura social. Isto é, condicionantes econômicos definem ainda hoje, numa sutileza copiosa, o espaço ocupado por cada cidadăo na sociedade. Althusser (1985) e Gramsci $(1978,1985)$, guardando o devido respeito às diferenças de ordem histórica, conceitual e epistemológica que caracterizam suas obras, contribuem ao entendimento da relação entre a nação organizada do ponto de vista político - 0 Estado - e os modos de produção e reprodução do modelo de organização social. Neste sentido, a instituição educacional pode atuar como promotora da ordem social, definindo o perfil de cidadão a ser forjado no seio escolar. Seja como aparelho ideológico a serviço do Estado, como nos diz o primeiro autor, seja como instrumento mantenedor do pensamento hegemônico, na fala do segundo, a escola participa efetivamente do processo de construção da cidadania dos indivíduos que a freqüentam. Contudo, a própria escola, por intermédio das pessoas que the dão vida, pode servir de espaço contestador dos determinantes sociais que a perpassam.

A colaboração de Buffa (1988) no desvelamento da função social da Educação indica-nos que a fim de perpetuar, e ao mesmo tempo incrementar os mecanismos de funcionamento do sistema sóciopolítico-econômico-cultural, "a Educação do povo é

* Professor da Universidade Estadual de Londrina. 
pensada e recomendada pelos teóricos da Educação"(p.54). Este comentário pode ser ilustrado pela Lei 5.692/71 (Brejon, 1976) quando esta confere ao ensino de $1^{\circ}$ e $2^{\circ}$ graus a "qualificação para o trabalho"(p.231) dos egressos da escola. Este fato acarretou ao sistema educacional mudanças implicadas às demandas econômico-sociais daquele momento histórico.

Pelo que nos indica Mello (1991), a escola encontra-se sufocada pela "necessidade de entrentar novos padrões de produtividade e competitividade"( $p$. 8). Este acontecimento leva em conta que "fatores de ordem econômica inter-relacionam-se com todas as dimensões da sociedade, apesar de não esgotar as possibilidades de entendimento do real"(Oliveira, V.M., 1994, p.32), refletindo-se também no contorno educacional. No que diz respeito ao conceito de competitividade, amplamente difundido nos setores econômicos, cumpre destacar que:

Encontramos tanto na Educação Física, como em nivel mais amplo na Educação, tendências pedagógicas liberais caracterizadas como tecnicista e competitivista (...) No caso específico da Educação Física, a competição sugere ganhar cada vez mais espaço nas práticas promovidas no cotidiano escolar (Cruz, 1995, p.16).

A assertiva supracitada pode ser nitidamente exemplificada no campo da Educação Física. Na esfera desportiva, mais contundentemente no alto nível, é comum ouvirmos palavras como: relação custo-beneficio, rendimento, produção, lucro. $O$ desporto de alto nivel produz um efeito cascata que ocasiona a reprodução dos fundamentos metodológicos destinados ao treinamento de seleções nacionais. Esse fenômeno atinge as escolinhas de iniciação desportiva, após passar pelas demais categorias que compõem o cenário desportivo. Partindo da premissa de que o referencial teórico-prático preponderantemente utilizado pela Educação Física escolar é o desporto competitivo - alto nivel - torna-se-nos clara a influência de elementos econômicos no trabalho promovido pela Educação Física. Essa invasão de termos econômicos vai além da fala dos professores e impregna pensamento e ação originados nesse contexto. Muito tem sido falado sobre as implicações sociais da Educação Fisica e dentre algumas dessas falas situa-se a de Soares et al. (1992), propondo exatamente que se desloque o eixo das açōes desenvolvidas do "jogar contra" para o "jogar com" (p.71), ou seja, que o frenesi competitivo ceda vez à homeostase cooperativa.

Seguindo o raciocínio iniciado neste trabalho, é coerente não desgarrar a Educação Física da Educação e da sociedade em seu sentido mais amplo. Em decorrência dessa opção para conduzir o presente artigo, năo posso furtar-me de recorrer aos dizeres de Capra (1982) a esse respeito, pois para ele "a autoafirmação excessiva manifesta-se como poder, controle e dominação de outros pela força; (...) A promoção do comportamento competitivo em detrimento da cooperação é uma das principais manifestações da tendência auto-afirmativa em nossa sociedade"(p. 41).

Ainda no tocante à competição, que invade os pátios e quadras escolares durante as aulas de Educação Física, deve-se atentar ao fato de que na opinião de Tani et al. (1988) "a competição está sempre orientada para um objetivo, havendo, neste sentido, uma interação positiva dentro das partes, mas negativa entre essas partes"( p.129). Não sei bem até que ponto concordo com a posição assumida pelos referidos autores, visto que, ao longo de minha atuação profissional não é pouco comum presenciar niveis exagerados de competição, inequivocadamente preponderantes na Educação Física escolar, capazes de comprometer esta "interação positiva dentro das partes". Os mesmos autores nos falam ainda de conflito como sendo "uma forma drástica de oposição que pode ser adotada pelos indivíduos. (...) um processo social que acentua as diferenças entre as pessoas e diminui as semelhanças" (p.131) podendo ainda "iniciar outras formas de interaçäo"(p.132).

O predomínio de uma Educação Física pautada quase que exclusivamente em jogos desportivos de caráter eminentemente competitivo deve ser no mínimo olhado com desconfiança. Indo mais além, ouso insinuar que tal constatação merece severas críticas por parte daqueles que acreditam na possibilidade de se praticar nas escolas uma Educação Física que não crie nos alunos a ilusão de serem atletas. É deveras temeroso pensar que se repetem, em boa parte de nossas escolas, métodos de trabalho vinculados diretamente ao desporto de alto nivel.

Mas convenhamos, não há possibilidade de almejar na escola desenvolvimento técnico-fisiológico que seja em escala semelhante à realidade clubística. As instalações, os recursos materiais, o número de sessões semanais, a quantidade de "alunos-atletas" envolvidos, enfim, toda a estrutura escolar se apresenta avessa à formação de atletas. Ademais, esse objetivo pseudo-educacional e ao mesmo tempo pseudo-desportivo não vem agradando já há algum tempo a uma boa parte de professores de Educação Física.

Faço minhas as palavras de Rubem Alves que de algum modo tangenciam a perplexidade ante a avassaladora presença de contornos competitivos na Educaçäo Física escolar: 
Tenho medo das Olimpíadas. Não por elas mesmas, mas pelos sonhos que elas lançam sobre todos aqueles que se movem no mundo da "educação física". Seu fascínio é grande. Seu poder de feitiço é imenso. E sua aura divina quase irresistivel... Gostaria que houvesse outros festivais em que a luta contra o tempo e contra o espaço fossem substituídas pelo prazer da travessia (1994, p. 42).

Contra as Olimpiadas? Certamente que não. Mas de fato apreensivo com as prováveis "caricaturizações" advindas de uma importação equivocada. As reflexōes iniciadas na década de 80 sobre os rumos da Educação Física no Brasil, traduzemse numa árdua busca de alternativas para essa área de conhecimento tão complexa quanto específica. $\mathrm{Na}$ tentativa de superar essa discussão, recorremos a Le Boulch (1995), que na intenção de apontar-nos um caminho neste sentido fala que a "Educação motora, que representa a forma contemporânea de uma Educação Física que se deseja científica, permanece um termo ambíguo podendo, de acordo com diferentes orientações, ter dois significados: Educação do movimento e Educação pelo movimento" (p.14).

A relação da Educação Física com o sistema escolar implica na inserção desta no que diz respeito ao sistema educacional. $E$ conseqüentemente define objetivamente sua participação na estrutura social que açambarca os sistemas educacional e escolar enquanto seus subsistemas (Betti, 1992). Isso não significa dizer que nas academias de ginástica, nos clubes ou nas horas de lazer, a Educação Física possa ser entendida como uma manifestação humana distanciada dos acontecimentos que rondam a sociedade. Daí podermos dizer que, principalmente em se tratando da Educação Física escolar, é inevitável a assunção de um posicionamento tanto político quanto pedagógico por parte da Educação Física.

Em se considerando a inserção da Educação Física na escola faz-se necessário, antes de mais nada, definir o que venha a ser essa instituição. Na percepção de Canivez (1991), podemos entendê-la como um "lugar onde se misturam as diferentes classes sociais, (...) um aparelho que permite a reprodução da hierarquia das classes sociais" (p.58). Essa permeabilidade característica do contorno escolar em relação à sociedade, implica num jogo de influências que nos faz lembrar a "dança cósmica" aludida por Capra (1983). A Educação Física é acolhida nesse emaranhado rítmico, e mais uma vez desvele-se aqui a imprescindibilidade de se articular o dia-a-dia escolar e os acontecimentos sociais em seu sentido mais amplo. Há que se convir na existência de: uma relação dialética entre o indivíduo e a sociedade, entre a consciência e a estrutura social, entre o corpo e a infraestrutura sócio-econômica, (...) É justamente esta relação que faz com que não se esvazie o papel da escola e da própria Educação como um todo, na sua função fundamental (...) de auxílio na transformação das estruturas sociais (Medina, 1991, p.19).

À Educação Física é facultada a opção de engajar-se, diria eu, em dois vieses distintos no modo de conceber sua atuação. De um lado o lidar com ossos, músculos e órgãos vitais, e de outro o entendimento de que nos propomos trabalhar com seres ímpares, bioenergéticos e, sobretudo, histórico-sociais. Não guardo aqui, no entanto, a intenção de sugerir um relacionamento maniqueísta entre as opções desenhadas, mas há que se observar, numa perspectiva crítico-social, que "as verdadeiras propostas (práticas) de trabalho na Educação Física, (...) são um projeto a ser construído em cada situação concreta onde elas pretendem se realizar por intermédio dos valores que conscientemente aceitem todos os participantes" (Medina, 1995, p.15, grifo meu).

Faz tempo que a Educação Física clama por uma participação efetiva no processo de formação de pessoas que sejam reconhecidas, e se reconheçam, além de seus músculos e demais atributos que satisfaçam os interesses gerados por determinadas condições econômico-sociais. Por isso devemos levar em conta a emergência, outrora denunciada, de que:

... a Educação Física escolar brasileira elabore a sua doutrina pedagógica, construa o seu projeto para a Educação brasileira, explicitando os seus valores e concepções de ser humano e sociedade, de modo a contribuir verdadeiramente para o desenvolvimento do sistema escolar (Oliveira, J.G.M., 1988, p.31).

Engrossando esse coro em favor de uma Educação Física que se assuma e pretenda transformadora, presenciamos o brado de Castellani Filho (1994), ainda aguardando que uma perspectiva transformadora seja abraçada por muitos nesta disciplina. Em sua opinião, aqueles envoltos por esse modo de se entender a Educação Física trazem consigo

... a percepção da necessidade de terem sempre presente em suas práticas, a certeza de que as atividades corporais devem se configurar como instâncias onde 
- Homem aprenda a construir uma sociedade justa. Isto porque estão convictos de que, enquanto profissionais da Educação Física, estarão a mais se não colaborarem (...) na construção de 'Homens capazes de transformarem o tempo em que vivem' (pp.221-222).

A Educação Física ainda passa por uma discussão a respeito da posição que deve ocupar em nossa paisagem social. Esse debate encarna aspectos culturais, econômicos, políticos e sociais que abraçam todo o mundo. Dentro da escola, a Educação Física observa de perto situaçōes que podem aparecer dissimuladas nas salas de aula, mas que são explícitas nos pátios e quadras. A separação muitas vezes sugerida pelos professores de Educação Física, tendo como parâmetros o sexo e o nível de habilidade motora, por exemplo, é reflexo de uma bagagem histórico-social, cultural e educativa que nos acompanha, assim como acompanhou nossos pais, os pais deles e por aí a fora. Contudo, essa postura reprodutiva pode ser radicalmente modificada, e como os demais segmentos sociais também a Educação Física, através de cada professor e em cada escola, deve optar pelo rumo a ser seguido.

É ingênuo pensar que a prática repensada da Educação Física possa reverter o quadro social atual. Mas, em contrapartida, é por demais perverso, senão negligente, participar desse processo sem nada fazer. Se é fato que "a Educação Física pode tornar-se uma força transformadora no projeto de humanização e emancipação do homem" (Gonçalves, 1994, p.178), já está mais do que na hora de rompermos com as fronteiras do pátio e adentrarmos em definitivo à escola.

Ao adentrarmos o universo da Educação Física escolar, mesmo dentro de uma perspectiva de transformação social, não podemos ignorar os liames existentes no relacionamento que se estabelece entre o indivíduo e a sociedade. Neste sentido, o corpo dos indivíduos abordados apresenta-se-nos como mediador da subjetividade humana e de sua estruturação social. Ou seja, ao pensarmos nas possibilidades de transformação social há que se levar em conta as modificações em nivel individual que se fazem necessárias à redefinição social. Portanto, a Educação Física escolar, amalgamada que está ao contexto sóciopolítico-econômico-cultural no qual se encontra inserida, e guardando a especificidade de adotar como instrumento de trabalho o corpo humano, não deve se descuidar dos efeitos que pode ocasionar na vida dos sujeitos que dela participam.

A respeito das maneiras de se intervir na realidade do outro através de seu corpo, Guattari e Rolnik (1993) nos falam que "o corpo, o rosto, a maneira de se comportar em cada detalhe dos movimentos de inserção social é sempre algo que tem a ver com o modo de inserçäo na subjetividade dominante" (p. 278). Essa posição é enriquecida por Santin (1992) ao afirmar que "entre dominantes e dominados da sociedade, há situações mais cômodas e outras mais constrangedoras que se configuram na vivência do corpo" (p. 86). O mesmo autor vai além e alerta os profissionais identificados com a intervenção no corpo do outro para a:

(...) necessidade da reflexão filosófica sobre o seu quê-fazer, deixando para velhos tempos o preconceito tolo de que só filósofos filosofam e também desconfiando de seus velhos vícios cientificistas, coisas estas que os têm relegado à posição de "tecnicões" de um corpo que não conhecem na devida profundidade (pp. 86-87).

Não podemos deixar, neste momento, de remeter nosso pensamento às formulaçöes de Foucault (1987) quando ele menciona os corpos docilizados através de mecanismos que os mantêm devidamente exercitados e obedientes, submissos enfim. Cabe então refletirmos sobre a adequabilidade de propostas "pedagógicas" na Educação Física apoiadas em pressupostos exclusivamente técnico-biológicos. A fim de se evitarem interpretações equivocadas em virtude desta reflexão, faz-se necessário recorrermos novamente a Santin (1992) quando este sinaliza-nos a importância de

(...) se interessar, em primeiro lugar, pelo corpo-objeto que interessa a anatomistas, fisiologistas e médicos. É esse corpo, objeto de conhecimento (corpo-problema), que se revela a nossos sentidos e nossa inteligência, a autêntica base da tematização da corporeidade em sua globalidade; todavia, "a posição absoluta de um só objeto é a morte da consciência", no sentido da paralização de tudo que o envolve, a ele se liga, explica-o e ultrapassa-o (pp. 85-86).

Se entendermos corporeidade como a manifestação materializada da subjetividade humana, e ao mesmo tempo admitirmos que essa reflete e é reflexo de características de uma estruturação social, vai-se clareando a impossibilidade de alheiarmo-nos das contradições que por vezes acompanham tanto nosso discurso quanto nossa ação. É inadmissível que se ocupe na Educação Física apenas de aspectos 
relacionados ao desenvolvimento biológico dos escolares que a vivenciam. Do mesmo modo que não é conveniente adotar-se uma postura quixotesca frente à problemática sócio-educativa da qual tomamos parte.

A dimensão anátomo-fisiológica na intervenção da Educação Física não pode ser preterida em detrimento de uma postura crítica quanto à sua participação social. Em contrapartida, é por demais empobrecedora a visão de que é possivel alijar-se de questões de ordem política, econômica ou social, pois estas atravessam-nos e se fazem presentes em nosso cotidiano. Trata-se à propósito de uma falsa dicotomia essa separação entre corpo individual e corpo social, não havendo a possibilidade de tocar em um sem atingir o outro.

Weil e Tompakow (1991), assim como Ehrenfried (1991) discorrem sobre a possibilidade de se modificar o individuo a partir de alterações em sua atitude física, envolvendo desde a postura até o tônus muscular. Já Alexander (1983) nos propõe a eutonia, que, atuando em nivel de tônus, respiração, contato e movimento, seria a "descoberta de si mesmo sem se retirar do mundo, mas ampliando sua consciência cotidiana" (p. 9). Indo além de tais proposições, podese perceber a partir do trabalho realizado por Del Priore (1993) o funcionamento de mecanismos de subjugação feminina através do corpo no período do Brasil Colônia, onde a autora constata que:

A igreja apropriou-se também da mentalidade androcêntrica presente no caráter colonial e explorou as relaçōes de dominação que presidiam o encontro de homem e mulher, incentivando a última a ser exemplarmente obediente e submissa. A relação de poder já implícita no escravismo reproduzia-se nas relações mais intimas entre marido e mulher, condenada esta a ser uma escrava doméstica, cuja existência se justificaşse em cuidar da casa, cozinhar, lavar a roupa, servir ao chefe da família com o seu sexo, dando-Ihe filhos quê assegurassem a sua descendência e servindo como modelo para a sociedade familiar com que sonhava a Igreja (p. 29, grifo meu).

Ao abordar questôes relacionadas à relação de poder que se estabelece no seio social em niveis macro e micro, Foulcault (1993) é enfático ao dizer que "nada mudará a sociedade se os mecanismos de poder que funcionam fora, abaixo e ao lado dos aparelhos de Estado a um nível muito mais elementar, cotidiano, não forem modificados" ( $p p$. 149-150). Para ele, o entendimento e superação da relação de poder instaurada em nossas vidas devem ser buscados nas ramificações oriundas do poder central, isto é menos na Esplanada dos Ministérios do que em nossas explanações cotidianas. Ora, sob essa ótica havemos de assumir nossa parcela de responsabilidade nos acontecimentos que permeiam o dia-a-dia escolar.

No que tange as relações de poder é muito comum justificativas para o nossa ação, ou inação, o fato de que os governantes não voltam os olhos para a questão educacional, mesmo sendo esta uma das prioridades constantes das propostas que antecedem ao mandato. Contudo, sem perder de vista o direito de, enquanto cidadãos, procedermos ao devido acompanhamento da atuação politica daqueles democraticamente eleitos pela maioria, é imprescindivel que, na condição de professores, olhemos para nós mesmos dentro desse processo. Pois bem, é fato que existem limitações político-administrativas para muitas das ações que desejamos realizar. Mas por que nos atermos àquilo que foge do nosso alcance imediato? Por que enxergar só o que não pode ser executado, perdendo de vista possibilidades que dependem prioritariamente de nós mesmos?

Certamente a assunção de um posicionamento consciente ante o quadro desenhado passa pela nossa visão de mundo, do outro e de suas manifestações corporais. A propósito, é deveras oportuno o acontecido por esses dias envolvendo uma modelo brasileira, representante legítima do modelo estético de corpo. A mesma viu-se impelida a, custasse - que custasse, não se distanciar das características corporais que a mantêm nessa condição. Cumpre nesse momento chamarmos atenção à dominação do desejo (Guattari, 1993) que extrapola os limites da dominação econômica e atinge-nos dissimuladamente dia após dia. Em sua arqueologia do saber, Foulcault (1987) mergulha nas intenções contidas por trás do discurso e, respeitando as diferenças de ordem filosófica, histórica e epistemológica, temos em Gardner (1994) indicações para se pensar no que possa vir a ser um saber-corporal. Deste modo, a percepção da subjetividade torna-se inquestionável ao nos referirmos ao corpo de escolares.

O saber-corpo remete-nos ao campo das ciências e logo então somos compelidos a ímaginar tratamentos estatísticos, tabelas e números, muitos números. Mas como quantificar a subjetividade humana? É possível ser científico com subjetividade? Faria Jr. e Farinatti (1992), Fazenda (1991) e Triviños (1987) discorrem com muita propriedade sobre a validade científica de procedimentos metodológicos que não dicotomizem a relação quantidade/qualidade em trabalhos cientificos. E na opinião de Rogers (1991):

A ciência apenas existe nas pessoas. Qualquer projeto científico tem o seu impulso criativo, o seu processo, a sua conclusão provisória, numa pessoa ou em 
várias pessoas. O conhecimento-mesmo o conhecimento científico - é aquele que é subjetivamente aceitável. O conhecimento científico só pode ser comunicado àqueles que estão subjetivamente preparados para receber a sua comunicação. A utilização da ciência apenas se dá através de pessoas que procuram valores que significam alguma coisa para elas (p.195).

Se concordarmos que ao pensar em sociedade vamos direta ou indiretamente passar pelo corpo daqueles que a constituem, e que para transformar as relaçōes sociais aí existentes é necessário contemplar o corpo desses indivíduos, torna-se-nos necessário atentar à indústria cultural e sua capacidade de fazer com que tudo se assemelhe, levando assim a um "empobrecimento dos materiais estéticos" (Adorno e Horkheimer, 1986, p.116). E por falar em estética, é conveniente perceber que "a criação estética encontrase sempre mergulhada na lógica social" (Baudrillard, p.32), e certamente também a estética corporal da qual nos (pre)ocupamos encontra-se nesse mar de contradições.

Mas, voltando à escola... Após essa breve, porém necessária digressão, quero compartilhar de uma indagaçăo sujeita a uma resposta aparentemente simples. Quando falamos de Educação Física na escola, de que escola falamos? Num primeiro momento ou vamos nos referir à escola pública ou privada. Num segundo instante vamos nos remeter ao $1^{\circ}$ ou $2^{\circ}$ graus. Gostaria portanto de desviar propositadamente o foco de atenção do $1^{\circ}$ e $2^{\circ}$ para o $3^{\circ} \mathrm{grau}$, não para refletir apenas sobre a Educação Física curricular, mas sobretudo para trazer à tona a questão da formação dos professores formados, formadores e formandos dos corpos-sujeitos com os quais trabalham ou virão trabalhar. Sob esse ângulo é possivel perceber que tanto quanto os freqüentadores das escolas de $1^{\circ}$ e $2^{\circ}$ graus, também os freqüentadores do $3^{\circ}$ grau se defrontam com aspectos relacionados à visão que têm do seu próprio corpo e do corpo do outro.

Atrelada à fala-ação de uma Educação Física transformadora, desde que seja essa a nossa opção, há que se vislumbrar as diversas maneiras de se conceber as atividades corporais às quais serão submetidos os sujeitos que compõe a sociedade. Por conseguinte, deve-se assumir uma posiçāo definida no que diz respeito ao entendimento das implicações pessoais e sociais relacionadas com a intervenção da Educação Física. Pode-se de um lado optar por formar corpos-escravos conformados com a "sorte" que the imputam, ou imputam a si mesmos, desconhecedores de seus próprios desejos, de sua subjetividade. Por outro lado, pode-se optar pela formação de corpos (auto)transformadores, mutáveis, capazes de perceberem a si próprios e ao outro em sua relaçāo com o todo social, passíveis de uma leitura estéticocorporal que não imponha limites, senão valorize a transcendência.

De fato não pretendi conferir a esse artigo um tom de originalidade. O tema Educação Física escolar, suas implicações sociais e a apropriação do corpo do outro, já há algum tempo vem sendo devidamente enfocado por autores como Betti, Castellani Filho, Medina, Moreira, Oliveira, Picollo, Soares e Tani, dentre outros. Estes autores vêm externando suas inquietações e, guardando suas diferenças epistemológicas, colaborando indiscutivelmente à ampliação do horizonte da Educação Física no Brasil. O que pretendo é, não mais que modestamente, aliar-me ao coro que brada por uma Educação Física que não se distancie de seu comprometimento para com os sujeitos abordados, a sociedade e nós mesmos, sem ignorar ou ordenar maniqueisticamente, as dimensões anátomofisiológicas, sócio-culturais, político-econômicas e instintivo-emocionais que caracterizam o homem e suas manifestaçōes corporais.

CRUZ, G. de C. Physical Education in the School: forming, conforming, transforming.

Semina: Londrina, Ci. Sociais/Humanas, v. 17, n. 3, p. 338-344, Sep. 1996.

ABSTRACT: In considering the possibilities of actions of Physical Education in the school, issues related to the social context in its broad sense emerge right away. Since the role of the school is to form the citizen, Physical Education shares part of the responsibility of such task. However, it is important to realize that this intervention in the school life will have its reflexions in the citizen to be. The intervention in the school's daily routine may cooperate as much for the conformation as for the transformation of the person and his/her social environment. A Physical Education based on theoretical-methodological underpinnings that are critical and creative and that aim at an affective participation in the school's social, political, and pedagogical project implies a radical rupture with the reductionist, sporting-competitive perspective, wich is predominant in our schools.

KEY-WORDS: Physical Education / School / Sports / Citizenship 


\section{REFERÊNCIAS BIBLIOGRÁFICAS}

ADORNO, T.W. \& HORKHEIMER, M. Dialética do esclarecimento. $2^{\mathrm{a}}$ ed. Rio de Janeiro: Jorge Zahar Ed., 1986.

ALEXANDER, G. Eutonia: um caminho para a percepçāo corporal. São Paulo: Martins Fontes, 1983.

ALTHUSSER, L. Aparelhos ideológicos de Estado. Rio de Janeiro: Ediçōes Graal, 1985.

ALVES, R. O corpo e as palavras. In: BRUHNS, H.T. (org.) Conversando sobre o corpo. $5^{\sharp}$ edição. Campinas - SP. Papirus, 1994

BAUDRILLARD, J. Para uma crítica da economia política do signo. Rio de Janeiro: Elfos Ed.: Lisboa: Edições 70, 1995.

BETTI, M. Educaçăo Física e sociedade. São Paulo: Editora Movimento, 1991.

BREJON, M. Estrutura e funcionamento do ensino de $1^{\circ}$ e $2^{\circ}$ graus. Sāo Paulo: Pioneira, 1976

BUFFA, E. Educação e cidadania. São Paulo: Cortez: Autores Associados, 1988.

CANIVEZ, P. Educar o cidadão? Campinas - SP: Papirus, 1991

CASTELLANI FILHO, L. Educaçăo Fisica no Brasil: a história que não se conta. $4^{\mathrm{a}}$ ed. Campinas - SP: Papirus, 1994.

CAPRA, F. O ponto de mutação. São Paulo: Editora Cultrix, 1982

O tao da física. $2^{a}$ ed. São Paulo: Editora Cultrix 1983.

CRUZ, G.C. Educação Física e a construçăo da cidadania. Sprint Magazine, XVI (79), 15-18, 1995.

DEL PRIORE, M. AO sul do corpo: condição feminina, maternidades e mentalidades no Brasil Colônia. Rio de Janeiro: José Olímpio: Brasília, DF: Edunb, 1993.

EHRENFRIED, L. Da educação do corpo ao equilíbrio do espírito. São Paulo: Summus, 1991.

FARIA JR. A.G. \& FARINATTI, P.T.V. Pesquisa e produção do conhecimento em educação física. Rio de Janeiro: Ao Livro Técnico, 1992.

FAZENDA, I. (org.) Metodologia da pesquisa educacional. $2^{a}$ ed. aumentada. São Paulo: Cortez, 1991.

FOUCAULT, M. Microfísica do poder. $11^{\text {a }}$ ed. Rio de Janeiro: Ediçōes Graal, 1993.

Vigiar e punir: nascimento da prisão. $9^{\mathrm{a}} \mathrm{ed}$ Petrópolis: Vozes, 1991.

Arqueologia do saber. $3^{a}$ ed. Rio de Janeiro: Forense-Universitária, 1987

GARDNER, $H$. Estruturas da mente: a teoria das inteligências múltiplas. Porto Alegre: Artes Médicas Sul, 1994.

GONÇALVES, M.A.S. Sentir, pensar, agir - Corporeidade e Educação. Campinas - SP: Papirus, 1994.
GRAMSCI, A. Maquiavel, a política e o Estado Moderno. Rio de Janeiro: Civilização Brasileira, 1987.

Os intelectuais e a organização da cultura. Rio de Janeiro: Civilização Brasileira, 1985.

GUATTARI, F. \& ROLNIK, S. Micropolitica: cartografias do desejo. $3^{a}$ ed. Petrópolis: Vozes, 1993.

GUATTARI, F. As três ecologias. $4^{a}$ ed. Campinas - SP: Papirus 1993.

LE BOULCH, J. O conceito de Educação motora. In DE MARCO, A.(org.) Pensando a Educação motora. Campinas - SP: Papirus, 1995.

MEDINA, J.P.S. A Educação física cuida do corpo e... "mente". $13^{\mathrm{a}}$ ediçăo. Campinas - SP: Papirus, 1995.

Papirus, 1991.

O brasileiro e seu corpo. $3^{a}$ ed. Campinas - SP:

MELLO, G.N. Políticas públicas de Educação. Estudos avançados. São Paulo: USP, v. 5, $n^{\circ} 13,1991, \mathrm{pp} .7-17$.

MOREIRA, W.W. Educação Física escolar: fundamentos de uma abordagem fenomenológica. São Paulo: EPU, 1991.

(org.). Educação Física \& esportes: perspectivas para o século XXI. Campinas - SP: Papirus, 1992.

O'DONNEL, G. A democracia no Brasil. São Paulo: Vértice, 1988.

OLIVEIRA, J.G.M. Educação Física e o ensino de $1^{2}$ grau: uma abordagem critica. São Paulo: EPU: EDUSP, 1988.

OLIVEIRA, V.M. Consenso e conflito da Educação Física brasileira. Campinas: Papirus, 1994.

PAIVA, V. Educação e bem-estar social. Educação e sociedade. $39,161-200,1991$.

PICOLLO, V.L.N. (org.) Educação Física escolar: ser ... ou não ter? $2^{\text {a }}$ ed. CAMPINAS - SP: Editora da Unicamp, 1993.

ROGERS, C.R. Tornar-se pessoa. $4^{a}$ ed. São Paulo: Martins Fontes, 1991.

SANTIN, S. Perspectivas na visão da corporeidade. In: MOREIRA, W.W. (org.) Educação Fisica e esportes: perspectivas para o século XXI. Campinas - SP: Papirus, 1992.

SOARES, C.L. et al. Metodologia do ensino de Educação Fisica. São Paulo: Cortez, 1992.

TANi, G. et al. Educaçāo Física escolar: fundamentos de uma abordagem desenvolvimentista. São Paulo: EPU: EDUSP, 1988.

TRIVIñoS, A.N.S. Introdução à pesquisa em ciências sociais: a pesquisa qualitativa em educação. São Paulo: Atlas, 1987.

WEIL, P. \& TOMPAKOW, R. O corpo fala: a linguagem silenciosa da comunicação não-verbal. $29^{\text {ed }}$ ed. Petrópolis: Vozes, 1991. 